\title{
Treatment of short stature and growth hormone deficiency in children with somatotropin (rDNA origin)
}

\author{
Dana S Hardin \\ Ohio State University and Columbus \\ Children's Hospital, Columbus, Ohio, \\ USA
}

\begin{abstract}
Somatotropin (growth hormone, GH) of recombinant DNA origin has provided a readily available and safe drug that has greatly improved management of children and adolescents with GH deficiency (GHD) and other disorders of growth. In the US and Europe, regulatory agencies have given approval for the use of GH in children and adults who meet specific criteria. However, clinical and ethical controversies remain regarding the diagnosis of GHD, dosing of GH, duration of therapy and expected outcomes. Areas which also require consensus include management of pubertal patients, transitioning pediatric patients to adulthood, management of children with idiopathic short stature and the role of recombinant IGF-1 in treatment. Additionally, studies have demonstrated anabolic benefits of GH in children who have inflammatory-based underlying disease and efficacy of GH in overcoming growth delays in people treated chronically with corticosteroids. These areas are open for possible new uses of this drug. This review summarizes current indications for GH use in children and discusses areas of clinical debate and potential anabolic uses in chronic illness.
\end{abstract}

Keywords: somatotropin, growth hormone deficiency, children, short stature

\section{Introduction}

Somatotropin (growth hormone, GH) of recombinant DNA origin has been commercially available since 1985 . It replaced human pituitary-derived GH, which was withdrawn for safety concerns. Regulatory agencies in Europe and North America have authorized its use for certain conditions based on data indicating safety and efficacy. The current approved conditions in the US include: growth hormone deficiency (GHD), idiopathic short stature (ISS), Turner syndrome (TS), Prader-Willi syndrome (PWS), chronic renal insufficiency (CRI), small for gestational age (SGA) and Noonan's Syndrome. Despite authorization for use, controversy remains. Concerns include cost versus benefit, and in some cases, safety. GH has known anabolic effects and several chronic illnesses have been studied by clinical trials to determine potential benefits of GH. Although several good summaries exist, this review is intended to extend these discussions. We will summarize benefits and controversies for approved GH indications in children, discuss current controversies in safety and efficacy and discuss potential anabolic use for chronic illness.

\section{Growth hormone deficiency}

Approximately 1 in 3500 children in the US are diagnosed with growth hormone deficiency (GHD) (Lindsay et al 1994). Only 20\% of these children have organic GHD. Organic causes include central nervous system tumors, radiation, infection, and traumatic brain injury. Approximately $80 \%$ of children do not have a readily identifiable cause of GHD. These patients are classified as having idiopathic GHD. 
In many US states, current insurance requirements require the use of secretagogue testing to diagnose GHD (Levy and Connelly 2003). However, a survey of pediatric endocrinologists in North America found that $95 \%$ of endocrinologists do not believe secretagogue testing is the best method of identifying who should be offered treatment with GH (Hardin et al 2007). This is in part due to the recognition that arbitrary cut-off values exist for defining GHD, the lack of reproducibility for test results and the fact that some children with remarkably abnormal growth velocity will have "normal" results to secretagogue testing. There may, however, be a resurgence of enthusiasm for stimulation testing due to the recent approval for recombinant IGF-1 to treat IGF-1 deficient children. Secretagogue testing or IGF-1 stimulation testing are needed to distinguish IGF-1 deficiency from GH deficiency. The consensus of opinion from pediatric endocrinologist's survey (Hardin et al 2007), the Growth Hormone Research Society (2000) and from the North American Lawson Wilkins Pediatric Endocrine Society (Wilson et al 2003) indicate that a diagnosis of GHD requires integration of auxologic criteria, medical history, laboratory tests, and radiologic assessments. Referral to an endocrinologist should be made for children with height $<3$ rd percentile, those with low growth velocity and those who demonstrate significant disparity between projected height and expected mid-parental height (Juul et al 1994).

Studies indicate that final adult height is increased with early therapy, thus the earlier the diagnosis, the better the prognosis for height. Furthermore studies indicate greater efficacy with larger GH doses, and continuous therapy (Blethen et al 1996; MacGillivray et al 1996, 1998). Thus it is important that primary care providers give early referral for evaluation of children with short stature, children with declining height percentiles, and for children not growing in concordance with their predicted adult height.

The duration of GH therapy is controversial. For many years, GH was given until epiphyseal fusion. New data suggests GH has important benefits for bone mineralization, lean mass (Saggese et al 1996; Underwood et al 2003; Boguszewski et al 2005) and improves cardiac risk factors, such as decreasing visceral adipose tissue and improving lipid profile (Colao et al 2002; Lanes et al 2003; Underwood et al 2003). These benefits have led to approval for GH treatment of adults (in lower doses) and suggest GH treatment should be life-long. Re-evaluation to determine if GH deficiency is persistent is indicated. Despite the recent development of guidelines for managing transitioning patients (Clayton et al 2005), differences in opinion remain regarding how and when this reassessment should be performed, the optimal GH dose in the transition period, and the respective roles of adult and pediatric providers in managing the endocrine care of transitioning patients.

Optimal dosing of GH during puberty is also controversial. In normal children, pubertal sex-steroid production independently stimulates growth and increases GH secretion, resulting in the pubertal growth spurt. Studies suggest that GHD patients may achieve greater pubertal growth if treated with GH doses higher than those used in prepubertal children (Codner et al 1997; Mauras et al 2000; Saenger 2003). However, controversy exists regarding the benefit in height versus the additional cost of therapy (Allen and Fost 2004). IGF-1 levels are specific for pubertal stage and gender, and good evidence suggests that monitoring IGF-I levels is useful in determining an optimal and safe GH dose (Park and Cohen 2004). At no time is this likely more important than during puberty. It seems logical that GHD children should have GH dosed according to maintenance of IGF-1 levels specific for pubertal stage and gender so that growth is maximized.

\section{Other FDA-approved indications Idiopathic short stature (ISS)}

Idiopathic short stature (ISS) is defined by a height 2.25 or more standard deviations below the mean (or less than the 1.2 percentile) for age and gender without evidence of underlying disease or GHD (Rekers-Mombarg et al 1999). This definition applies to approximately 400,000 children in the US and includes a diverse group of patients. In the US, the FDA approved GH for ISS in 2003. Similar approval does not exist in Europe. The degree of height improvement resulting from GH treatment of ISS children varies depending on the research study (Hintz et al 1999; Finkelstein et al 2002; Leschek et al 2004; Kemp et al 2005). Use of GH for the ISS indication remains controversial, in part due to the variability in reported height improvement, but also due to poorly defined measures of therapeutic success (eg, improved psychosocial adjustment), and debate about whether the goal of treatment should be simply a "normal" height or "maximum" height (Allen and Fost 2004). There is little consensus among endocrinologists about GH use in children with ISS and unfortunately it has led to dissention in the Endocrine community (Hardin et al 2007). Further complicating matters is the increased public awareness of the ISS indication resulting in requests for therapy with GH. Evaluation by a specialist is recommended for children with heights at the 3rd percentile or less, and poor growth velocity. Early referral (before puberty) will provide time for a greater height benefit 
should treatment be needed. The endocrine community needs to explore the polarization on this topic and seek tolerance for diversity of opinion.

\section{Turner syndrome (TS)}

Girls with TS have an abnormal or missing X chromosome, resulting in short stature and ovarian failure (Saggese et al 1996). TS occurs in 1 in 2,500 live female births, making it a common cause of short stature in girls. Variability in phenotypic features often contributes to a delay in diagnosis; therefore, karyotyping is recommended for any young female with unexplained short stature (height below 5 th percentile), delayed puberty, or any clinical features of TS (Savendahl and Davenport 2000). GH therapy increases the growth rate and final adult height of girls with TS (Sas et al 1999; Chernausek et al 2000). Studies indicate the improvement in growth is related to the dose and duration of therapy before the initiation of estrogen replacement therapy (Chernausek et al 2000). Some studies suggest addition of oxandrolone adds to final height (Rosenfeld et al 1998; Sas et al 1999; Chernausek et al 2000; Reiter et al 2001). The dose of GH recommended for treatment of TS is $0.375 \mathrm{mg} / \mathrm{kg} /$ week (Rosenfeld et al 1998). A recent study (Davenport et al 2007) clearly suggests that GH therapy before the age of five is safe and improves final height. Early diagnosis promotes coordination of management strategies to prevent TS-related morbidities (eg, cardiovascular and otologic) and may also increase adult height by allowing a longer duration of $\mathrm{GH}$ therapy before initiation of estrogen replacement (Reiter et al 2001).

\section{Chronic renal insufficiency (CRI)}

Short stature is common in children with CRI. Several reasons contribute to the pathogenesis including metabolic acidosis, water-electrolyte disturbances, protein-calorie malnutrition, renal osteodystrophy, and corticosteroid treatment which create resistance to the action of GH (Kuizon and Salusky 1999; Roelfsema and Clark 2001). Abnormalities in the GH-IGF-I axis may also contribute (Roelfsema and Clark 2001). Most patients with renal disease have high levels of GH secondary to decreased renal clearance; however, they also have decreased numbers of $\mathrm{GH}$ receptors, increased production of IGF-binding proteins and a reduction in bioavailable IGF-I. Despite these metabolic alterations, studies have demonstrated that GH therapy significantly increases linear growth (Fine et al 1994a; Hokken-Koelega et al 2000; Haffner et al 2000), bone mineral density (Van Dyck et al 2001), body weight, and lean mass in CRI (Fine et al 1994b).
Moreover, GH does not accelerate the progression of renal insufficiency or hasten the need for dialysis (Tonshoff et al 1992). Although CRI is an FDA-approved indication, GH use for these patients has been limited $(<10 \%$ of children registered in the North American Pediatric Renal Transplant Cooperative Study) (Study 2005). One possible reason is the lack of adult height data since only recent trials have included adult height as an end point (Fine et al 1994b). Furthermore, height may be perceived as a less serious concern in the setting of other complex medical problems experienced by children with CRI. Nevertheless, growth failure remains a significant clinical problem in these children, and treatment with GH should be started as soon as possible. The continuation of GH after renal transplantation is still a matter of controversy and long-term, post-transplant studies are needed.

\section{Prader-Willi syndrome (PWS)}

In the US the FDA approved GH for treatment of PWS in 2000. PWS is a genetic disorder caused by deletion or lack of expression of a portion of the paternally derived chromosome 15 and occurs in approximately 1 in 25,000 births. Although diagnostic criteria are available (Gunay-Aygun et al 2001), the non-specific features of PWS in infancy often contribute to a delayed diagnosis. Clinical findings include a decline in linear growth, as well as hypotonia, hyperphagia, obesity, hypogonadism, sleep disorders, and behavioral abnormalities (Goldstone 2004). Hypothalamic dysfunction results in GHD. The efficacy of GH therapy in improving linear growth, physical strength and agility, and body composition in children with PWS is well documented (Carrel et al 1999, 2001, 2002). A recent study (Carrel et al 2004) demonstrates safety and efficacy in infants. Studies also demonstrate positive changes in lipid profile and increased muscle force (Haqq et al 2003). A recent dosing recommendation proposes use of $0.24 \mathrm{mg} / \mathrm{kg} /$ week based on ideal body weight (Lindgren and Ritzen 1999). Sudden death has been reported in 17 children with PWS who were treated with GH (Van Vliet et al 2004). These children had underlying early presentation of morbid obesity (BMI 31-42 kg/m²), respiratory, and/or possible sleep disorders, and in general were very young (Eiholzer 2005). It remains possible, but not certain, that GH therapy might have contributed to these deaths (Van Vliet et al 2004; Eiholzer 2005). If GH were a contributing factor, the leading hypothesis as to the cause is that of airway obstruction from soft tissue hypertrophy; however, to date there is no published evidence that such hypertrophy contributed to these deaths. Most endocrinologists now recommend sleep studies and correction of underlying airway obstruction prior to initiating 
GH treatment (Allen and Carrel 2004). Many clinicians believe that the benefits of $\mathrm{GH}$ treatment outweigh the risks in children with PWS; however, there is still debate.

\section{Small for gestational age (SGA)}

Approximately 90,000 infants are born SGA in the US each year (Lee et al 2003). Most exhibit postnatal growth acceleration and have adequate catch-up growth by age 2 , with most catch up growth occurring in the first 6 months (Kelnar 2003a). It is important to know that in pre-term infants, growth acceleration can be delayed up to age 5 years (Boonstra et al 2003). Despite adequate growth in most patients, in approximately $10 \%$ of patients, the pattern of growth continues to be abnormal with height $<-2.5$ SDS (Davenport 2005).

GH was approved for children born SGA in 2001 in the US and in Europe in 2003. The reported benefits of GH in increasing final adult height and bone mineral density in children born SGA support evaluation for possible treatment (Arends et al 2003; Van Pareren et al 2003; Dahlgren and Wikland 2005). Endocrinologists should rule out other potential causes for poor growth before treating, but clearly treatment should be offered when other causes have been excluded. Aspects of treatment needing on-going study include determining the optimal dose and duration of treatment. Recent studies (Hokken-Koelega et al 1995; Drake et al 2001) suggest that children who initiate GH during mid to late childhood, and those with growth retardation below 3 SDS, may need higher doses of GH than traditional dosing. Many children born SGA have additional medical problems and have documented risk for metabolic disorders including hypertension, hyperlipidemia, insulin resistance, and cardiovascular disease (later life) (Harris et al 2004). Monitoring for these problems is important for the endocrinologist and the primary care physician.

\section{Short bowel syndrome (SBS)}

GH has been approved for SBS therapy in the US for patients receiving "specialized nutritional support" including highcarbohydrate, low-fat diet, enteral or parenteral nutrition and patients receiving certain elemental diets (Zorbtive). The approval was not limited to a specific age, yet no specific pediatric trials were presented to the FDA. The adult studies used to garner approval documented decreased need for parenteral nutrition when GH was given for 6 weeks. Studies are needed to determine optimal dose and duration of therapy for pediatric patients. The current recommended dose is $0.1-0.8 \mathrm{mg} / \mathrm{kg}$ daily (Zorbtive). In adults with SBS, the administration of GH has promoted significant improvement in nutrient absorption, body weight, and lean body mass (Seguy et al 2003). Studies are needed in children.

\section{Noonan's syndrome}

Noonan's syndrome, an autosomal dominant condition occurring in 1:1000-1:2500 live births, is the most recent FDA approved indication for GH therapy. The syndrome is characterized by some clinical features similar to Turner syndrome and include: short stature, pulmonary valvular stenosis, facial dysmorphy and hypertelorism, thoracic cage excavation, paddle neck, moderate mental retardation, deafness, hypogonadism, cryptorchidism, and coagulation abnormalities (Asokan et al 2007). There appears to be GH/IGF-1 axis abnormalities. Studies have indicated that GH improves height in these children; however, most trials have been small (Kirk et al 2001; Kelnar 2003b). One group of Noonan syndrome patients, those with a gene mutation in PTPN 11, have lower basal height (Ferreira et al 2005). This gene is responsible for GH/IGF-1 signal transduction in cells and some small reports suggest Noonan's patients with this mutation may have less response to GH (Kirk et al 2001). It is possible the recombinant IGF-1 therapy may provide better growth than $\mathrm{GH}$ in this patient subset; studies are needed.

\section{Off-label clinical applications that have shown potential benefit}

Chronic illness in children is often associated with poor growth which may be related to the underlying disorder, to poor nutrition, or to the administration of growth-inhibiting drug therapies such as glucocorticoids. In all chronic illnesses, poor growth has been linked to less favorable clinical outcomes. Thus several chronic conditions have sparked investigation of GH as an anabolic agent.

Although FDA approval of GH therapy for adults with AIDS wasting has been obtained, use in HIV-infected and AIDS wasted children is considered off-label. Children infected with HIV frequently exhibit decreased growth velocity compared to healthy age-matched children (Saavedra et al 1995). This growth decline has been shown to correlate significantly with viral burden (Johann-Liang et al 2000, Arpadi et al 2000). GH therapy has been shown to increase height and weight in children infected with HIV but has not been associated with an increase in viral burden (Hardin et al 2005b).

Multiple studies (Alemzadeh et al 1998; Hardin et al 1998, 2001, 2005a), including two large multi-center trials (Hardin et al 2006; Schnabel et al 2007), have demonstrated 
good improvement in linear growth, body weight, lean mass, and bone mineral content and reduces hospital admissions in children with cystic fibrosis.

In Europe, but thus far not the US, GH has been approved for use to reverse steroid-mediated growth failure for patients with juvenile inflammatory arthritis. Not only has GH been shown to decrease loss of growth velocity in these children, but to also promote accretion of bone and muscle mass (Bechtold et al 2005). Studies in children with poor growth resulting from treatment with glucocorticoids for any reason demonstrated, on average, a doubling of growth rate in response to rhGH (Allen et al 1998).

Finally, GH has been shown to significantly increase fat-free mass, bone mineral accretion, weight gain, and linear growth without adversely affecting disease activity or carbohydrate tolerance in children who have inflammatory bowel disease (IBD) (Mauras et al 2002). Although beneficial effects of GH may be important to individuals with these conditions, it is uncertain whether approval for these indications is forthcoming; therefore endocrinologists need to determine the appropriateness of GH therapy on an individual-patient basis and prescribe the drug "off-label".

\section{Safety}

Prior to recombinant GH, Creutzfeldt-Jakob disease occurred in some patients treated with contaminated pituitary-derived GH (Hintz 1995). Once recombinant GH was produced, patient registries were established to allow long-term safety monitoring in a large number of patients. Data from the largest registries include the Kabi International Growth Study (KIGS) including children from the US and Europe, and the National Cooperative Growth Study (NCGS), which includes only children from the US. Both registries indicate that longterm use of GH is not associated with an increased risk of primary leukemia or other malignancies in patients who have not had pre-existing blood-born or solid tumors (Blethen et al 1996; Maneatis et al 2000). They also demonstrate that although GH can reduce insulin sensitivity, the incidence of diabetes mellitus in children treated with $\mathrm{GH}$ is similar to that expected in the general population (Bell et al 2005). Other problems have been rarely reported and include: benign intracranial hypertension, slipped capital femoral epiphysis, scoliosis, pancreatitis, and adrenal insufficiency (Mills et al 2004). In general, these events represent heightened sensitivity to the physiological effects of GH (eg, sodium and water retention, growth rate acceleration) or the unmasking of underlying conditions of treated patients. Endocrinologists must carefully monitor pituitary hormone levels and clinical status in patients prior to and during GH treatment (Growth Hormone Research Society 2001). However, there is clear consensus among endocrinologists that the benefits of $\mathrm{GH}$ outweigh its risks (Hardin et al 2007).

\section{Cost and controversy}

Eligibility for treatment with $\mathrm{GH}$ is one of the most controversial areas in pediatric endocrinology. Members of the Lawson Wilkins Pediatric Endocrinology Society cited the cost as one major factor limiting their prescribing of the drug (Hardin et al 2007). Prescribing choices are increasingly limited by hospital or insurance formulary decisions. At the present time, all pharmaceutical companies that produce GH charge similar prices for the drug and injection devices. Therefore careful investigation regarding dose and duration of therapy is indicated for all approved and off-label uses.

\section{Conclusion}

The increased availability and demonstrated efficacy and safety of recombinant GH have greatly expanded the scope of GH use. Virtually all indications and potential uses for GH need further study regarding optimal dosing and duration of therapy. New findings regarding the metabolic and anabolic effects of $\mathrm{GH}$ have prompted application for new indications and have increased off-label use of this drug. The new indication in the US for ISS prompts further questions about the morbidity of shortness, the value of treating short stature medically, and how best to define and measure the ultimate goals of GH therapy. Finally, the new interest and potential uses for GH have sparked controversy within the pediatric endocrinology community. It is important that members of this specialty realize that differing points of view exist and that there is room for tolerance for diverse opinion regarding treatment eligibility. Until more research is done, this field cannot be approached as a black and white, right or wrong, scenario.

\section{Disclosures}

The author reports no conflicts of interest.

\section{References}

Alemzadeh R, Upchurch L, McCarthy V. 1998. Anabolic effects of growth hormone treatment in young children with cystic fibrosis. $J$ Am Coll Nutr, 17:419-24.

Allen DB, Carrel AL. 2004. Growth hormone therapy for PraderWilli syndrome: a critical appraisal. J Pediatr Endocrinol Metab, 17(Suppl 4):1297-306.

Allen DB, Fost N. 2004. hGH for short stature: ethical issues raised by expanded access. J Pediatr, 144:648-52.

Allen DB, Julius JR, Breen TJ. et al. 1998. Treatment of glucocorticoidinduced growth suppression with growth hormone. National Cooperative Growth Study. J Clin Endocrinol Metab, 83:2824-9. 
Arends NJ, Boonstra VH, Mulder PG, et al. 2003. GH treatment and its effect on bone mineral density, bone maturation and growth in short children born small for gestational age: 3-year results of a randomized, controlled GH trial. Clin Endocrinol Oxf, 59:779-87.

Arpadi SM, Cuff PA, Kotler DP, et al. 2000. Growth velocity, fat-free mass and energy intake are inversely related to viral load in HIV-infected children. J Nutr, 130:2498-502.

Asokan S, Muthu MS, Rathna Prabhu V. 2007. Noonan syndrome: a case report. J Indian Soc Pedod Prev Dent, 25:144-7.

Bechtold S, Ripperger P, Bonfig W, et al. 2005. Growth hormone changes bone geometry and body composition in patients with juvenile idiopathic arthritis requiring glucocorticoid treatment: a controlled study using peripheral quantitative computed tomography.J Clin Endocrinol Metab, 90:3168-73.

Bell JJ, Bolar K, Swinford RD, et al. 2005. Long-term safety of recombinant human growth hormone: the National Cooperative Growth Study Experience [poster]. 87th Annual Meeting of the Endocrine Society; June 4-7, 2005; San Diego, CA. p.2-450.

Blethen SL, Allen DB, Graves D, et al. 1996. Safety of recombinant deoxyribonucleic acid-derived growth hormone: The National Cooperative Growth Study experience. J Clin Endocrinol Metab, 81:1704-10.

Boguszewski CL, Meister LH, Zaninelli DC, et al. 2005. One year of GH replacement therapy with a fixed low-dose regimen improves body composition, bone mineral density and lipid profile of GH-deficient adults. Eur J Endocrinol, 152:67-75.

Boonstra V, Van Pareren Y, Mulder, P, et al. 2003. Puberty in growth hormone-treated children born small for gestational age SGA. J Clin Endocrinol Metab, 88:5753-8.

Carrel AL, Moerchen V, Myers SE, et al. 2004. Growth hormone improves mobility and body composition in infants and toddlers with Prader-Willi syndrome. J Pediatr, 145:744-9.

Carrel AL, Myers SE, Whitman BY, et al. 1999. Growth hormone improves body composition, fat utilization, physical strength and agility, and growth in Prader-Willi syndrome: A controlled study. J Pediatr, 134:215-21.

Carrel AL, Myers SE, Whitman BY, et al. 2001. Sustained benefits of growth hormone on body composition, fat utilization, physical strength and agility, and growth in Prader-Willi syndrome are dose-dependent. J Pediatr Endocrinol Metab, 14:1097-105.

Carrel AL, Myers SE, Whitman BY, et al. 2002. Benefits of long-term GH therapy in Prader-Willi syndrome: a 4-year study. J Clin Endocrinol Metab, 87:1581-5.

Chernausek SD, Attie KM, Cara JF, et al. 2000. Growth hormone therapy of Turner syndrome: the impact of age of estrogen replacement on final height. Genentech, Inc., Collaborative Study Group. J Clin Endocrinol Metab, 85:2439-45.

Clayton PE, Cuneo RC, Juul A, et al. 2005. Consensus statement on the management of the GH-treated adolescent in the transition to adult care. Eur J Endocrinol, 152:165-70.

Codner E, Mericq V, Cassorla F. 1997. Optimizing growth hormone therapy during puberty. Horm Res, 48(Suppl 5):16-20.

Colao A, Di Somma C, Pivonello R, et al. 2002. The cardiovascular risk of adult GH deficiency GHD. improved after GH replacement and worsened in untreated GHD: a 12-month prospective study. $J$ Clin Endocrinol Metab, 87:1088-93.

Dahlgren J, Wikland KA. 2005. Final height in short children born small for gestational age treated with growth hormone. Pediatr Res, 57:216-22.

Davenport ML, Crowe BJ, Travers SH, et al. 2007. Growth hormone treatment of early growth failure in toddlers with Turner syndrome: a randomized, controlled, multicenter trial. J Clin Endocrinol Metab, 92:3406-16.

Davenport ML, Quigley CA, Bryant CG, et al. 2005. Effects of early growth hormone GH. treatment in very young girls with Turner Syndrome TS. Presented at 7th Join ESPE/LWPES Meeting; Lyon, France; 2005.

Drake WM, Howell SJ, Monson JP, et al. 2001. Optimizing GH therapy in adults and children. Endocr Rev, 22:425-50.
Eiholzer U. 2005. Deaths in children with Prader-Willi syndrome. A contribution to the debate about the safety of growth hormone treatment in children with PWS. Horm Res, 63:33-9.

Ferreira LV, Souza SA, Arnhold IJ, et al. 2005. PTPN11 protein tyrosine phosphatase, nonreceptor type 11. mutations and response to growth hormone therapy in children with Noonan syndrome. J Clin Endocrinol Metab, 90:5156-60

Fine RN, Kohaut EC, Brown D, et al. 1994a. Growth after recombinant human growth hormone treatment in children with chronic renal failure: report of a multicenter randomized double-blind placebocontrolled study. Genentech Cooperative Study Group. J Pediatr, 124:374-82.

Fine RN, Yadin O, Moulton L, et al. 1994b. Five years experience with recombinant human growth hormone treatment of children with chronic renal failure. J Pediatr Endocrinol, 7:1-12.

Finkelstein BS, Imperiale TF, Speroff T, et al. 2002. Effect of growth hormone therapy on height in children with idiopathic short stature: a meta-analysis. Arch Pediatr Adolesc Med, 156:230-40.

Goldstone AP. 2004. Prader-Willi syndrome: advances in genetics, pathophysiology and treatment. Trends Endocrinol Metab, 15:12-20.

Growth Hormone Research Society. 2000. Consensus guidelines for the diagnosis and treatment of growth hormone $\mathrm{GH}$. deficiency in childhood and adolescence: summary statement of the GH Research Society. $J$ Clin Endocrinol Metab, 85:3990-3.

Growth Hormone Research Society 2001. Critical evaluation of the safety of recombinant human growth hormone administration: statement from the Growth Hormone Research Society. J Clin Endocrinol Metab, 86:1868-70.

Gunay-Aygun M, Schwartz S, Heeger S, et al. 2001. The changing purpose of Prader-Willi syndrome clinical diagnostic criteria and proposed revised criteria. Pediatrics, 108:E92.

Haffner D, Schaefer F, Nissel R, et al. 2000. Effect of growth hormone treatment on the adult height of children with chronic renal failure. German Study Group for Growth Hormone Treatment in Chronic Renal Failure. N Engl J Med, 343:923-30.

Haqq AM, Stadler DD, Jackson RH, et al. 2003. Effects of growth hormone on pulmonary function, sleep quality, behavior, cognition, growth velocity, body composition, and resting energy expenditure in Prader-Willi syndrome. J Clin Endocrinol Metab, 88:2206-12.

Hardin DS, Adams-Huet B, Brown D, et al. 2006. Growth hormone treatment improves growth and clinical status in prepubertal children with cystic fibrosis: results of a multicenter randomized controlled trial. J Clin Endocrinol Metab, 91:4925-9.

Hardin DS, Ellis KJ, Dyson M, et al. 2001. Growth hormone improves clinical status in prepubertal children with cystic fibrosis: results of a randomized controlled trial. J Pediatr, 139:636-42.

Hardin DS, Rice J, Ahn C, et al. 2005a. Growth hormone treatment enhances nutrition and growth in children with cystic fibrosis receiving enteral nutrition. J Pediatr, 146:324-8.

Hardin DS, Rice J, Doyle ME, et al. 2005b. Growth hormone improves protein catabolism and growth in prepubertal children with HIV infection. Clin Endocrinol Oxf, 63:259-62.

Hardin DS, Stratton R, Kramer JC, et al. 1998. Growth hormone improves weight velocity and height velocity in prepubertal children with cystic fibrosis. Horm Metab Res, 30:636-41.

Hardin DS, Woo J, Butsch R, et al. 2007. Current prescribing practices and opinions about growth hormone therapy: results of a nationwide survey of paediatric endocrinologists. Clin Endocrinol Oxf, 66:85-94.

Harris M, Hofman PL, Cutfield WS. 2004. Growth hormone treatment in children: review of safety and efficacy. Paediatr Drugs, 6:93-106.

Hintz RL. 1995. The prismatic case of Creutzfeldt-Jakob disease associated with pituitary growth hormone treatment. J Clin Endocrinol Metab, 80:2298-301.

Hintz RL, Attie KM, Baptista J, et al. 1999. Effect of growth hormone treatment on adult height of children with idiopathic short stature. Genentech Collaborative Group. N Engl J Med, 340:502-7. 
Hokken-Koelega A, Mulder P, De Jong R, et al. 2000. Long-term effects of growth hormone treatment on growth and puberty in patients with chronic renal insufficiency. Pediatr Nephrol, 14:701-6.

Hokken-Koelega AC, De Ridder MA, Lemmen RJ, et al. 1995. Children born small for gestational age: do they catch up? Pediatr Res, 38:267-71.

Johann-Liang R, O’Neill L, Cervia J, et al. 2000. Energy balance, viral burden, insulin-like growth factor-1, interleukin- 6 and growth impairment in children infected with human immunodeficiency virus. Aids, 14:683-90.

Juul A, Bang P, Hertel NT, et al. 1994. Serum insulin-like growth factor-I in 1030 healthy children, adolescents, and adults: relation to age, sex, stage of puberty, testicular size, and body mass index. J Clin Endocrinol Metab, 78:744-52.

Kelnar CJ. 2003a. Growth hormone therapy for syndromic disorders. Clin Endocrinol Oxf, 59:12-21.

Kelnar CJ. 2003b. The role of somatropin therapy in children with Noonan syndrome. Treat Endocrinol, 2:165-72.

Kemp SF, Kuntze J, Attie KM, et al. 2005. Efficacy and safety results of long-term growth hormone treatment of idiopathic short stature. J Clin Endocrinol Metab, 90:5247-53.

Kirk JM, Betts PR, Butler GE, et al. 2001. Short stature in Noonan syndrome: response to growth hormone therapy. Arch Dis Child, 84:440-3.

Kuizon BD, Salusky IB. 1999. Growth retardation in children with chronic renal failure. J Bone Miner Res, 14:1680-90.

Lanes R, Paoli M, Carrillo E, et al. 2003. Cardiovascular risk of young growth-hormone-deficient adolescents. Differences in growthhormone-treated and untreated patients. Horm Res, 60:291-6.

Lee PA, Chernausek SDHokken-Koelega AC, et al. 2003. International Small for Gestational Age Advisory Board consensus development conference statement: management of short children born small for gestational age, April 24-October 1, 2001. Pediatrics, 111:1253-61.

Leschek EW, Rose SR, Yanovski JA, et al. 2004. Effect of growth hormone treatment on adult height in peripubertal children with idiopathic short stature: a randomized, double-blind, placebo-controlled trial. J Clin Endocrinol Metab, 89:3140-8

Levy RA, Connelly K. 2003. Diagnostic growth hormone deficiency testing practices among patients in the NCGS/NCSS databases. J Pediatr Endocrinol Metab, 16(Suppl 3):619-24.

Lindgren AC, Ritzen EM. 1999. Five years of growth hormone treatment in children with Prader-Willi syndrome. Swedish National Growth Hormone Advisory Group. Acta Paediatr Suppl, 88:109-11.

Lindsay R, Feldkamp M, Harris D, et al. 1994. Utah Growth Study: growth standards and the prevalence of growth hormone deficiency. J Pediatr, 125:29-35.

MaCgillivray MH, Baptista J, Johanson A. 1996. Outcome of a four-year randomized study of daily versus three times weekly somatropin treatment in prepubertal naive growth hormone-deficient children. Genentech Study Group. J Clin Endocrinol Metab, 81:1806-9.

MaCgillivray MH, Blethen SL, Buchlis JG, et al. 1998. Current dosing of growth hormone in children with growth hormone deficiency: how physiologic? Pediatrics, 102:527-30.

Maneatis T, Baptista J, Connelly K, et al. 2000. Growth hormone safety update from the National Cooperative Growth Study. J Pediatr Endocrinol Metab, 13(Suppl 2):1035-44.

Mauras N, Attie KM, Reiter EO, et al. 2000. High dose recombinant human growth hormone $\mathrm{GH}$. treatment of GH-deficient patients in puberty increases near-final height: a randomized, multicenter trial. Genentech, Inc., Cooperative Study Group. J Clin Endocrinol Metab, 85:3653-60.

Mauras N, George D, Evans J, et al. 2002. Growth hormone has anabolic effects in glucocorticosteroid-dependent children with inflammatory bowel disease: a pilot study. Metabolism, 51:127-35.
Mills JL, Schonberger LB, Wysowski DK, et al. 2004. Long-term mortality in the United States cohort of pituitary-derived growth hormone recipients. J Pediatr, 144:430-6.

Park P, Cohen P. 2004. The role of insulin-like growth factor I monitoring in growth hormone-treated children. Horm Res, 62(Suppl 1):59-65.

Reiter EO, Blethen SL, Baptista J, et al. 2001. Early initiation of growth hormone treatment allows age-appropriate estrogen use in Turner's syndrome. J Clin Endocrinol Metab, 86:1936-41.

Rekers-Mombarg LT, Kamp GA, Massa GG, et al. 1999. Influence of growth hormone treatment on pubertal timing and pubertal growth in children with idiopathic short stature. Dutch Growth Hormone Working Group. J Pediatr Endocrinol Metab, 12:611-22.

Roelfsema V, Clark RG. 2001. The growth hormone and insulin-like growth factor axis: its manipulation for the benefit of growth disorders in renal failure. J Am Soc Nephrol, 12:1297-306.

Rosenfeld RG, Attie KM, Frane J, et al. 1998. Growth hormone therapy of Turner's syndrome: beneficial effect on adult height. $J$ Pediatr, 132:319-24.

Saavedra JM, Henderson RA, Perman JA, et al. 1995. Longitudinal assessment of growth in children born to mothers with human immunodeficiency virus infection. Arch Pediatr Adolesc Med, 149:497-502.

Saenger P. 2003. Dose effects of growth hormone during puberty. Horm Res, 60:52-7.

Saggese G, Baroncelli GI, Bertelloni S, et al. 1996. The effect of long-term growth hormone $\mathrm{GH}$. treatment on bone mineral density in children with GH deficiency. Role of GH in the attainment of peak bone mass. J Clin Endocrinol Metab, 81:3077-83.

Sas TC, De Muinck Keizer-Schrama SM, Stijnen T, et al. 1999. Normalization of height in girls with Turner syndrome after long-term growth hormone treatment: results of a randomized dose-response trial. J Clin Endocrinol Metab, 84:4607-12.

Savendahl L, Davenport ML. 2000. Delayed diagnoses of Turner's syndrome: proposed guidelines for change. J Pediatr, 137:455-9.

Schnabel D, Grasemann C, Staab D, et al. 2007. A multicenter, randomized, double-blind, placebo-controlled trial to evaluate the metabolic and respiratory effects of growth hormone in children with cystic fibrosis. Pediatrics, 119:e1230-8.

Seguy D, Vahedi K, Kapel N, et al. 2003. Low-dose growth hormone in adult home parenteral nutrition-dependent short bowel syndrome patients: a positive study. Gastroenterology, 124:293-302.

STUDY, N. A. P. R. T. C. 2005. Annual Report.

Tonshoff B, Tonshoff C, Mehls O, et al. 1992. Growth hormone treatment in children with preterminal chronic renal failure: no adverse effect on glomerular filtration rate. Eur J Pediatr, 151:601-7.

Underwood LE, Attie KM, Baptista J. 2003. Growth hormone GH. doseresponse in young adults with childhood-onset GH deficiency: a two-year, multicenter, multiple-dose, placebo-controlled study. J Clin Endocrinol Metab, 88:5273-80.

Van Dyck M, Gyssels A, Proesmans W, et al. 2001. Growth hormone treatment enhances bone mineralisation in children with chronic renal failure. Eur J Pediatr, 160:359-63.

Van Pareren Y, Mulder P, Houdijk M, et al. 2003. Adult height after longterm, continuous growth hormone GH. treatment in short children born small for gestational age: results of a randomized, double-blind, doseresponse GH trial. J Clin Endocrinol Metab, 88:3584-90.

Van Vliet G, Deal CL, Crock PA, et al. 2004. Sudden death in growth hormonetreated children with Prader-Willi syndrome. J Pediatr, 144:129-31.

Wilson TA, Rose SR, Cohen P, et al. 2003. Update of guidelines for the use of growth hormone in children: the Lawson Wilkins Pediatric Endocrinology Society Drug and Therapeutics Committee. J Pediatr, 143:415-21.

Zorbtive $^{\circledR}$ somatotropin rDNA origin. for injection. EMD Serono, Inc. www.zorbitive.com. 
